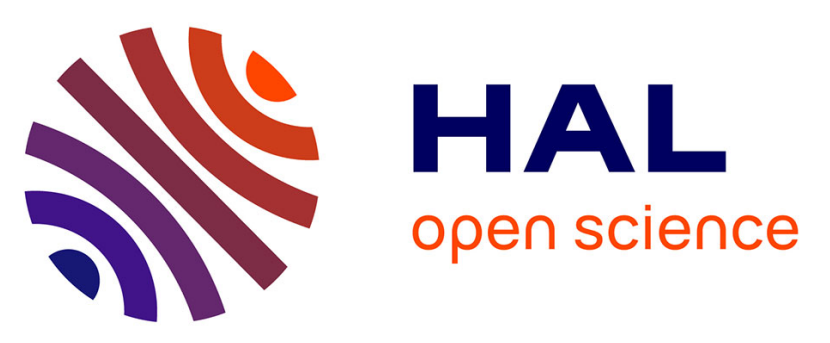

\title{
Towards a Knowledge based Support for Risk Engineering When Elaborating Offer in Response to a Customer Demand
}

Rania Ayachi, Delphine Guillon, François Marmier, Élise Vareilles, Michel Aldanondo, Thierry Coudert, Laurent Geneste, Yvan Beauregard

\section{To cite this version:}

Rania Ayachi, Delphine Guillon, François Marmier, Élise Vareilles, Michel Aldanondo, et al.. Towards a Knowledge based Support for Risk Engineering When Elaborating Offer in Response to a Customer Demand. IEEM 2018 - International Conference on Industrial Engineering and Engineering Management, Dec 2018, Bangkok, Thailand. pp.1056 - 1060, 10.1109/IEEM.2018.8607699 . hal-01969496

\section{HAL Id: hal-01969496 https://hal.science/hal-01969496}

Submitted on 4 Jan 2019

HAL is a multi-disciplinary open access archive for the deposit and dissemination of scientific research documents, whether they are published or not. The documents may come from teaching and research institutions in France or abroad, or from public or private research centers.
L'archive ouverte pluridisciplinaire HAL, est destinée au dépôt et à la diffusion de documents scientifiques de niveau recherche, publiés ou non, émanant des établissements d'enseignement et de recherche français ou étrangers, des laboratoires publics ou privés. 


\title{
Towards a Knowledge based Support for Risk Engineering When Elaborating Offer in Response to a Customer Demand
}

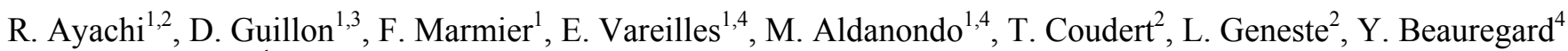 \\ ${ }^{1}$ Industrial Engineering Center, Toulouse University - IMT Mines Albi, Albi, France \\ ${ }^{2}$ Laboratoire de Génie de Production, Toulouse University - INP-ENIT, Tarbes, France \\ ${ }^{3}$ ESTIA Recherche - Bidart - France \\ ${ }^{4}$ Mechanical Engineering, École de Technologie Supérieure, Montréal, Canada \\ (corresponding author e-mail: michel.aldanondo@mines-albi.fr)
}

\begin{abstract}
This paper deals with the first ideas relevant to a knowledge based support for risk engineering when answering tenders or direct customer demands. Indeed, when an offer is defined, it becomes more and more important to analyze the possibilities of: risks occurrence, their consequences and their potential avoidance. Most of the time if it is done, this analysis is conducted manually thanks to a risk expert. In this paper, we propose to assist the expert with a risk engineering aiding tool that relies on a knowledge base and which allows to define and evaluate: (i) the risk and its probability, (ii) the main risk impacts and (iii) the interests of various corrective and preventive actions (impact and probability reductions). We first detail the problem. Then we identify risk knowledge and risk processing. This allows us proposing a knowledge model relevant to the risk engineering entities and some knowledge retrieval queries to support risk engineering.
\end{abstract}

Keywords Customer/supplier relation, offer elaboration, risk engineering, knowledge based system, knowledge model, case base reasoning.

\section{INTRODUCTION}

\subsection{Company context and risk in offer elaboration}

This paper deals with offer elaboration when answering call for tenders or direct customer demands. The offer concerns physical product or mechanical systems, called indistinctly in the rest of the paper systems. The customer/supplier relation is assumed to be in a B2B context and in a "light" Engineer To Order situation (ETO) [1]. By light ETO we mean that more than $75 \%$ of the systems are configured to order (CTO), either assembly or make to order (ATO or MTO); the $25 \%$ left, are engineer to order (ETO). Globally, such systems are mainly standard but allow some customer specific options that are non-standard, also called ETO options [2]. These ETO options are a strong point for the supplier's competitiveness.

During the offer elaboration, as there is no guarantee that the customer accepts the offer, we assume that the supplier doesn't study in detail: (i) the design of every ETO option, (ii) their integration with the standard solution and (iii) their production process. The supplier just characterizes the key parameters of the ETO options (among them performance and cost). As a consequence, when the customer accepts the offer, the supplier must design in detail every ETO option, their integration and production process before launching production. This is where the risky point lies as explained by [3]. As the offer has been submitted and accepted with given performance, cost and due date, without a detail study of the ETO options, the supplier takes the risk of not being able to match what he has promised and sold. This means that the final delivered system might be more expensive and/or longer to produce than expected.

\subsection{Offer elaboration and risk engineering}

We assume that the offer elaboration is achieved thanks to a concurrent system/process engineering activity supported by:

- a system configuration software in order to configure the CTO part of the system that has some kind of a "design gate" for ETO enabling the user to capture the rough ideas about the solution relevant to ETO options [4], [5]. - a delivery process configuration software in order to be able to configure the design activity (for ETO options) and the production activities (for the whole system, from sourcing, assembling up to installing and test) [6].

The risk, previously characterized, is therefore attached to the delivery process. Therefore, following the system/process engineering activity, a second activity is concerned with the risks engineering relevant to the delivery process as shown in Fig.1.

This risk engineering activity, scope of this paper, most of

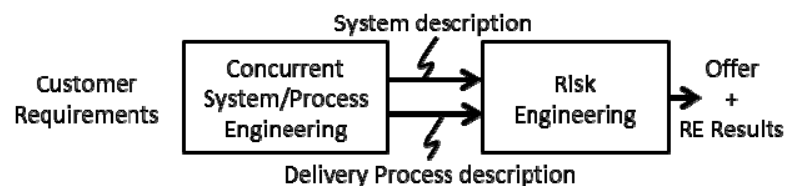

Fig. 1 - Offer elaboration and risk engineering

the time relies on human expertise. In order to be less human expert dependent and to increase the risk expert confidence our goal is to provide some knowledge based support to the person in charge of this second activity.

Similarly to knowledge based engineering fundamentals and more specifically configuration key ideas [7], we consider that it should be possible to gather risk engineering knowledge in a knowledge base, as a kind of generic model, and to propose some kind of knowledge interactive process that allows exploiting this knowledge in order to support risk engineering for a specific risk. In 
accordance with this purpose, the rest of this article goes as follows: after a short literature survey, a second section characterizes the knowledge involved in risk engineering and risk processing, then in the third section, previous knowledge is turned into a model and some knowledge retrieval queries that can support risk engineering when elaborating offers are proposed.

\subsection{Related works}

According to [8], risk engineering in new product development projects can go as follows. The delivery process is considered as the main input. In our situation, the delivery process gathers a sequence of tasks as: finalize design, source sub-systems and/or raw-materials, manufacture, assemble, test and deliver. Each of these tasks is analyzed by a risk expert who identify for each task: (i) the negative event that can be associated to the risk with its occurrence probability, (ii) the impacts of this event as modifications of the cost or duration of some tasks, (iii) the possible corrective or preventive actions, in order to counter the risk and (iv) the impacts reductions and/or risk probability reductions as a result of these corrective or preventive actions. Our goal is so far to establish a knowledge model and an interactive process to support the person in charge of these identifications that we call risk engineering.

With regard to risks in the customer-supplier relationship domain, most of the works are based on marketing approaches, logistics issues or supplier selection [9] or [10]. We retain the work of [10] because: (i) they propose a classification of the risks according to the type of customer-supplier relationship, (ii) they clearly differentiate the risks "buyer" and "seller" and (iii) they stress the need to consider the supplier's point of view. Our work is fully in line with this last point. Regarding the risks in offer elaboration, we did not find any work addressing the problem as we formulated it.

On the other hand, there is more works and normative elements concerning the risks in project management [11]. We are part of this workflow and especially in the continuity of the approaches proposed in [8] and [12], where a notion of risk processing strategy is proposed. Regarding the modeling and exploitation of risk knowledge to support offer elaboration in customersupplier relationship, the work is much rarer. Some works exist in civil engineering [13] or in information system project [14]. As far as we know, only [13] proposes knowledge modeling elements for risks. We join in this type of contribution and will propose elements of knowledge models.

\section{II - RISK IDENTIFICATION IN THE DELIVERY PROCESS}

\subsection{Identification of risk engineering inputs}

As seen in section 2.1 the delivery process logically constitutes a first input of risk engineering, because the risks and their impacts and treatments will be defined with respect to the tasks of this delivery process. We describe this process as follows:

- The delivery process is associated with a system that is the subject of an offer. A same system can be associated with several delivery processes, in order to compare process variants.

- A process is broken down into tasks linked by precedence constraints. Each task $\mathrm{i}$ is performed by a key resource (resource needed to perform it) and is characterized by a cost, ci, and a duration, di, (other metrics could be defined) as shown in Fig. 2 .

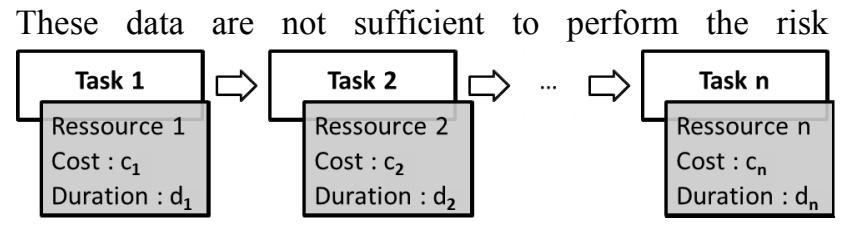

Fig. 2 - Process subject to Risk Engineering

engineering. Other data relevant to the engineered system or the general context of the offer have to be taken into account by the expert. System characteristics impacting the risk engineering can be for example: the complexity or the size of the system, the maturity of the technologies employed, the reliability of the components used, etc. General context of the offer impacting the risk engineering can be for example: the importance of the customer, the recurrence of the demand, the workload of the supplier, etc.

The risk expert has the knowledge about these characteristics and their impacts on the tasks of the delivery process. They strongly modulate the values of risk probabilities, impacts and impact reductions. We propose to describe these characteristics using the triplet:

(1) Conceptual element, for example: crane system, engine component, offer, customer, etc.

(2) Attribute describing the conceptual elements, e.g. crane complexity, engine maturity, offer recurrence, importance of customer, etc.

(3) Value of the attribute describing the concept, for example, very strong / strong / weak / very weak, high / medium / low.

Of course for example : (i) an offer of a high complexity crane with a low maturity engine will be more risky and (ii) risk processing and impact reductions will be stronger if the customer is important.

As a conclusion two inputs will be used by the expert, the delivery process description and the conceptual elements attributes that impacts risk engineering.

\subsection{Risk engineering knowledge identification}

We have seen in section 1.3 that the expert identifies: (i) risk probability, (ii) risk impacts, (iii) corrective preventive actions, (iv) and reduction of impacts and probabilities. We propose in this section to identify the 
risk knowledge brought by the expert during this engineering task.

\subsubsection{Risk probability}

We consider the risk as a pair (task, event), meaning that the event that occurs during this task correspond with the risk. This is questionable but makes it possible to dissociate the analysis of the consequences of the same event on different tasks. For example, this allows the event "Snowfall and blocked road" to be analyzed differently, depending on whether it occurs during a "Component sourcing" task or during a "Final delivery to customer" task.

A risk is characterized by the probability of occurrence of the associated event, on the task identified.

A single task can be the source of several risks. For example, a "Finalizing the design" task can be subject to two risks "Task more difficult than expected" and "Key resource unavailable".

\subsubsection{Risk impacts}

A risk is associated with a set of impacts. For example, the risk " Finalizing the design task more difficult than expected" can have two impacts, one on the "Finalizing design" task and the other on the "Assembling and testing" task. An impact is defined for a single risk with:

(1) the impacted task,

(2) the nature of the impact: cost or duration (or other),

(3) the method of calculating the impact: either additive or multiplicative,

(4) the value of the impact.

A given task can be the object of several impacts resulting from different risks $\mathrm{Ri}$. It will then undergo an overall cost impact (Ic) and an overall impact duration (Id), calculated as follows:

- each multiplicative impact is calculated individually with respect to the characteristics of the task,

- all multiplicative and additive impacts are then summed.

So, if we consider:

- aci: Impact additive cost of risk Ri,

- mci: Impact multiplicative cost of risk Ri,

- adi: Impact additive delay of risk Ri,

- mdi: Impact multiplicative delay of risk Ri,

the two global impacts are as follows:

$I c=\sum_{i}\left(a c_{i}+c \times m c_{i}\right)$
$I d=\sum_{i}\left(a d_{i}+d \times m d_{i}\right)$

$I d=\sum_{i}\left(a d_{i}+d \times m d_{i}\right)$

Given all these elements and according to the approach advocated in [8] that proposes to use a discrete event simulator to simulate the delivery process with all possible combinations of risk occurrences ; it is already possible to compute all possible triplet (cost, duration, probability) of the delivery process relevant to an offer. This is a first level of risk engineering that allows knowing "what could happen if things don't go as they should". As an example, the illustration in Fig. 3 shows a case with two risks with probabilities of 0.1 and 0.01 . Logically in the left part, with no risk occurrence (prob $0.891)$, cost and duration are minimized while they are maximized if the two risks occur (prob 0.001).
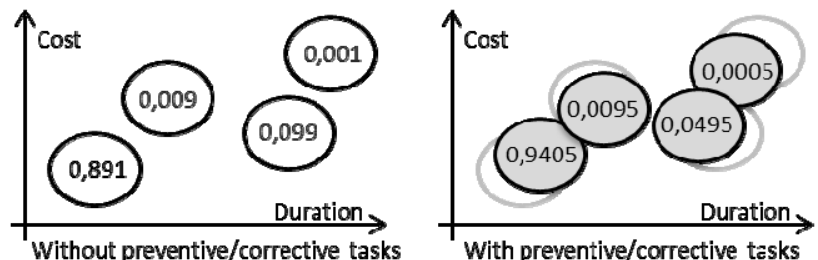

Fig. 3 - Process and risk impacts

\subsubsection{Corrective and preventive actions, risk strategies}

This is the key job of the risk expert. To cope with these impacts, the risk expert defines local treatment strategies. A local treatment strategy is defined for one risk and includes: (i) a set of corrective and / or preventive actions, (ii) a set of impact reductions and possibly (iii) a reduction in the probability of occurrence of the risk.

Each corrective or preventive action is a task related to the tasks of the delivery process by precedence constraints. A corrective or preventive task can be associated with different local strategies of the same risk. Each corrective or preventive action is characterized by a duration and a cost.

Each impact reduction is defined for a local strategy and for a task impacted by the risk. A reduction is defined by:

(1) the impacted task object of the impact reduction,

(2) the nature of the impact reduction: cost or duration,

(3) the method of calculating the impact reduction that is always proportional,

(4) the value of the impact reduction.

A given task can be subject to several impact reductions. We make the assumption that each impact reduction is carried out homogeneously on all the additive and multiplicative impacts. The overall impact cost reductions (RIc) and duration (RId) are thus calculated as follows: - each impact reduction is calculated individually in relation to the value of the impact,

- the impact reductions are then added.

So, if we consider:

- redci: Impact reduction cost strategy risk $\mathrm{Ri}$

- reddi: Impact reduction duration risk strategy $\mathrm{Ri}$ the two impact reductions are as follows:

$R I c=\sum_{i}\left[\operatorname{redc}_{i} \times\left(a c_{i}+c \times m c_{i}\right)\right]$

$R I d=\sum_{i}\left[\right.$ redd $\left._{i} \times\left(a d_{i}+d \times m d_{i}\right)\right]$

Given these elements and according to the same idea of using a discrete event simulator to simulate the delivery process. It is now possible to evaluate risk strategies and select the relevant corrective and preventive actions as it can be seen in the right part of Fig. 3 where a preventive action reduces a risk probability from 0.1 to 0.05 . 


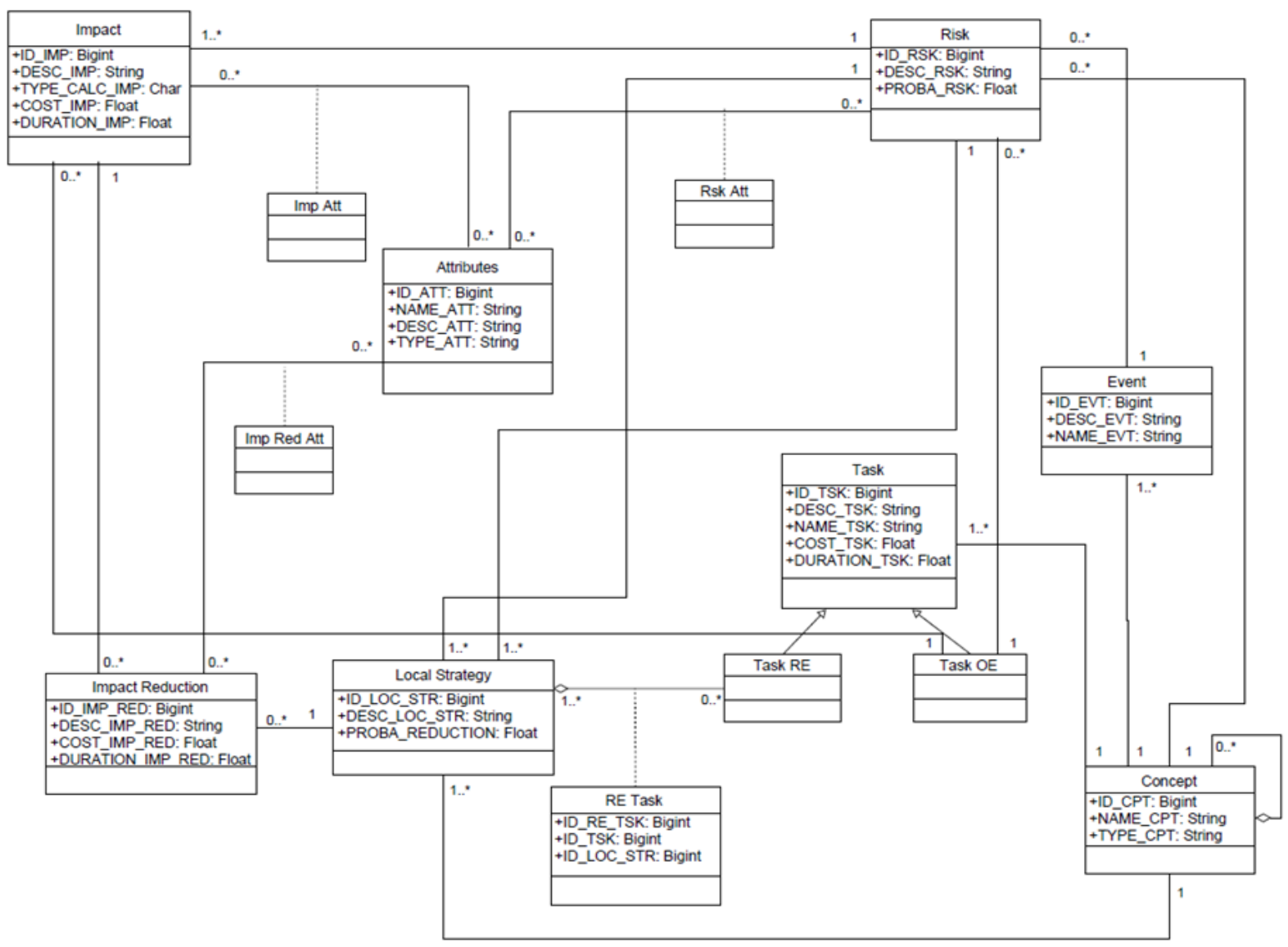

Fig. 4 - Risk engineering knowledge model

\section{III - TOWARDS A KNOWLEDGE BASED SYSTEM FOR SUPPORTING RISK ENGINEERING}

\subsection{The risk engineering knowledge model}

Previous elements allow us proposing the following knowledge model.

In the right part of Fig. 4, the delivery process tasks, correspond to the Task OE (Offer Elaboration) class. The corrective and preventive tasks proposed by the expert are described in the Task RE (Risk Engineering) class. These two tasks are generalized in the Task class. The event is defined in an Event class. A risk is defined with the Risk class, for a single task and a single event (link 1). Human reasoning or the support knowledge based system needs to abstractly characterize and link these three entities (task, event, risk). When the expert decides to associate a risk to a task, he uses his knowledge and mentally associates, for example, a type of event with a type of task and deduces a risk. This knowledge is modeled by the notion of concept, which we define in the Concept class. In the left part of Fig. 4, the impact is represented by the Impact class. An impact points only to one risk and one impacted task (link 1). The local strategy is represented by the Local Strategy class. A local strategy focuses only on one risk (link 1). It includes corrective and/or preventive tasks and impact reductions (link $0 .{ }^{*}$ ) and possibly a single probability reduction. Impact reduction is represented by the class Impact Reduction. The reduction points to a single impact and a single local strategy (link 1).

Last key point, the conceptual elements attributes that impact risk engineering are in the center left of Fig. 4. As for concepts, this knowledge is stored by the Attribute class with its associations with the Risk, the Impact and the Impact Reduction classes.

\subsection{Aiding risk engineering with queries.}

Based on the principles of reasoning by analogy or casebased reasoning [15], our idea is to store in a case base all the information describing the effective realization of past delivery processes (these processes correspond to offers accepted by the customer, otherwise the process would not be realized). Then, in the presence of a new or current offer, the objective is to look for similar items in the case base and retrieve the risk information required for risk engineering in order to provide it as a suggestion to the person in charge of the risk engineering. Three examples of queries relevant to risk, risk impact and risk strategies are proposed.

The first query proposes, for a given task, possible risks with probabilities as follows:

(i) for a given task of a current process offer, identify its task concept,

(ii) select in the case base, the risks where associated task concept is same or similar to the given task concept,

(iii) select from the selected risks, the risks and their probabilities with conceptual element attributes same or 
similar to those of the current offer, propose these results to the person in charge.

The second query proposes, for a given risk, possible impacted tasks with impacts values as follows:

(i) for a given risk and associated task of a current process offer, identify its risk and task concepts,

(ii) select in case base, the impacted tasks affected by a risk with same or similar concept to the given risk concept,

(iii) select from the selected impacted tasks, the impacted tasks and their impacts values with conceptual element attributes same or similar to those of the current offer, propose these results to the person in charge.

The last query proposes, for a given risk, possible strategies with corrective/preventive tasks and impacts reductions as follows:

(i) for a given risk and associated task of a current process offer, identify its risk and task concepts,

(ii) select in current offer, the impacted tasks and impacted values defined in the second query, identify the impacted task concepts,

(iii) select in the case base, the risk strategies with their corrective/preventive tasks and impact reductions with same or similar to previously founded impacted tasks concepts,

(iv) select from selected risk strategies, corrective/ preventive tasks and impact reductions values with conceptual element attributes same or similar to those of the current offer, propose these results to the person in charge.

These three queries are given as examples. Other one can be established. They provide a strong support to the person in charge of risk engineering in the sense that they avoid him to rely only on his own knowledge or risk expertise.

\section{CONCLUSION}

The goal of this short article was to provide first elements in order to set-up to a knowledge based support system for risk engineering when answering tenders or direct customer demands. Risk engineering knowledge has been identified, a knowledge model was provided with example of queries to assist risk engineering.

Two main interests of this proposition are (i) to support and to give confidence to the risk expert suggestions, (ii) and to allow being less human expert dependent. Another key interest of this proposition is to allow companies: (i) to reduce the level of expertise required to engineer conventional risks (with a junior risk expert for example) and (ii) to leave more times to the senior expert to focus on unconventional risks (new risks or critical risks, for example).

As far as we know, we did not find any scientific work relevant to this problem. We are at the present time beginning to prototype and test this knowledge base system with four companies. Next issues is to add some rule based decision aiding, assuming that some generic risk engineering rules can be extracted from the case base.

\section{ACKNOWLEDGMENT}

The authors would like to thank all ANR OPERA partners and the French ANR agency for work funding.

\section{REFERENCES}

[1] Rivest L., Desrochers A., Brie A., 2010, Adaptive generic product structure modelling for design reuse in engineer-toorder products, Computers in Industry Vol 61 pp 53-65.

[2] Markworth S., Hvam L., 2018, Understanding the impact of non-standard customisations in an engineer-to-order context: A case study, Int. J. of Production Research, in press 2018.

[3] Sylla A., Vareilles E., Coudert T., Kirytopoulos K., Aldanondo M., Geneste L, 2017, Readiness, feasibility and confidence: how to help bidders to better develop and assess their offers, Int. J. of Production Research, Vol. 55, No. 23, pp 7204-7222,

[4] Sylla A., Guillon D., Vareilles E., Aldanondo M., Coudert T., Geneste L., 2018, Configuration knowledge modeling: How to extend configuration from assemble/make to order towards engineer to order for the bidding process, Computers in Industry Vol 99 pp 29-41.

[5] Vareilles E., Aldanondo M., Gaborit P., 2007, Evaluation and design: A knowledge-based approach, Int. J. of Computer Integrated Manuf., Vol. 20, No. 7, pp 659-653,

[6] Zhang L., Vareilles E., Aldanondo M., 2013, Generic Bill of Functions, Materials, and Operations for SAP 2 Configuration, Int. J. of Production Research Vol 51, No 2, pp 465-478

[7] Felfernig A., Hotz L., Bagley C., Tiihonen J., 2014, Knowledge-Based Configuration From Research to Business Cases, Ed Morgan Kaufmann.

[8] Marmier F., Gourc D., Laarz F, 2013, A risk oriented model to assess strategic decisions in new product development projects, Decision Support Systems Vol 56 pp. $74-82$

[9] Thun J.H., Hoenig D., 2011, An empirical analysis of supply chain risk management in the German automotive industry Int. J. of Production Economics Vol 131, No 1, pp 242-249

[10] Hallikas J, Puumalainen K., Vesterinen T., Virolainen V., 2005, Risk-based classification of supplier relationships, J. of Purchasing and Supply Manag. Vol 11, No 2-3, pp. 7282

[11] ISO 31000, 2009. International Standards for Business, Risk Management - Principles and Guidelines.

[12] Fang C., Marle F., 2012, A simulation-based risk network model for decision support in project risk management, Decision Support Systems Vol 52, pp. 635-644.

[13] Yildiz A.E., Dikmena I., Birgonul M.T., Ercoskunb K., Alten S., 2014, A knowledge-based risk mapping tool for cost estimation of international construction projects, Automation in Construction Vol 43, pp.144-155

[14] Alhawaria S., Karadshehb L., Talet A.N., Mansoura E., 2012, Knowledge-Based Risk Management framework for Information Technology project, Int. J. of Information Manag. vol 32 pp. 50 - 65

[15] Romero J., Coudert T., Vareilles E., Geneste L., Aldanondo M., Abeille J., Case-Based reasoning and system design: An integrated approach based on ontology and preference modeling - Artificial Intelligence for Eng., Des., Anal. and Manuf.(AI-EDAM), Vol. 28, n²1, pp. 49-69, 2014. 